\title{
High success rate of liver and kidney transplant during seven months COVID-19 period
}

\author{
Emre Karakaya', Aydincan Akdur ${ }^{1}$, Ebru Ayvazoglu Soy ${ }^{1}$, Feza Yarbug Karakayali', Sedat Yildirim', Adnan Torgay ${ }^{2}$, \\ Cihat Burak Sayin ${ }^{3}$, Gokhan Moray ${ }^{1}$, Mehmet Haberal ${ }^{1}$

\footnotetext{
${ }^{1}$ Department of General Surgery, Baskent University Hospital, Turkey

${ }^{2}$ Department of Anaesthesia and Reanimation, Baskent University Hospital, Turkey

${ }^{3}$ Department of Nephrology, Baskent University Hospital, Turkey
}

Background: During the pandemic, so many centers have postponed transplant surgery. In the present study, we aimed to evaluate our liver and kidney transplant during the pandemic period.

Methods: During 7 months in the pandemic period, we performed 49 kidneys and 14 liver transplant. Before the transplant procedure, all candidates were screened for coronavirus 2019 (COVID-19). Also, we recorded transplantation age, sex, graft type, post-transplant laboratory values complications, and length of stay.

Results: In this period we performed 49 kidney and 14 liver transplants. In the kidney group, five recipients were a child. Thirty-two patients (65\%) were male. Adult kidney recipients' mean age was 39.5 years and children were 4, 6, 14, 15, and 16 years. Recipients were treated in transplant service after surgery. All patients were discharged with normal laboratory values. In the liver transplant group, ten patients were a child and four patients were adults. All liver transplants were living donor liver transplants. The mean age of child patients was 24.2 months. One liver recipient died due to oxalosis induced heart failure and one liver recipient died due to intracranial bleeding. Other patients were discharged with normal liver functions. Both kidney and liver donors were discharged without any problem.

Conclusions: Our results showed that transplant surgery can be performed during a pandemic safely with the exclusion of COVID.

Corresponding author: Emre Karakaya

E-mail: rectorate@baskent.edu.tr

(c) The Korean Society for Transplantation

This is an Open Access article distributed under the terms of the Creative Commons Attribution Non-Commercial License (http://creativecommons.org/licenses/by-nc/4.0/) which permits unrestricted non-commercial use, distribution, and reproduction in any medium, provided the original work is properly cited. 